\title{
Fabrication of Silicon Oxycarbide-Based Microcomponents via Photolithographic and Soft Lithography Approaches
}

\author{
E. Ionescu ${ }^{1}$, S. Martinez Crespiera ${ }^{1}$, M. Schlosser ${ }^{1}$, K. Flittner $^{2}$, H. F. Schlaak ${ }^{2}$, R. Riedel ${ }^{1}$ \\ ${ }^{1}$ Technische Universität Darmstadt, Institut für Materialwissenschaft, \\ Fachgebiet Disperse Feststoffe, Petersenstraße 23, 64287 Darmstadt \\ ionescu@materials.tu-darmstadt.de \\ ${ }^{2}$ Technische Universität Darmstadt, Institut für Elektromechanische Konstruktionen, \\ Merckstraße 25, 64283 Darmstadt
}

\begin{abstract}
:
This study presents the preparation of ceramic micro components starting from a commercially available polysiloxane. The ceramic micro components were prepared via photolithographic and soft litho graphy approaches. The ceramic samples prepared upon photolithography exhibit aspect ratios of $3: 1$ as well as dimensions down to $20 \mu \mathrm{m}$. Furthermore, soft lithographic techniques have been used to prepare dense, crack free and complex-shaped SiOC-based micro components (e.g., a valve seat for a miniaturized burner).
\end{abstract}

Key words: ceramic micro components, photolithography, soft lithography, silicon oxycarbide.

\section{Introduction}

Ceramic-based micro electromechanical systems (i.e., MEMS) have found increased interest in the last decades, since they exhibit high potential for applications in harsh environments, e.g. sensors in engines and turbines, micro burners, chemical micro reactors etc $[1,2,3]$. However, their processing is rather difficult and expensive, since shaping of the ceramic micro component cannot be achieved by using conventional techniques used for sha?ping ceramic monoliths. Thus, new shaping techniques are required for the preparation of micro components. Among them, lithographic approaches have been shown to be promising and reliable for the processing of ceramic microsized components.

Within this context the fabrication of ceramic micro components upon shaping and pyrolysis of preceramic polymers has been given in the last time more and more interest, since it allows for producing complex shaped components. The fabrication of the micro components is performed either via direct microstructuring techniques (such as lithographic processes, i.e. UV-, X-ray, E-beam or laser-assisted lithography) $[4,5]$ or by means of softlithographic techniques (which allow for shaping elastic and thermoplastic materials). [6]
For this purpose preceramic polymers are used, e.g. poly(carbo)silanes, poly(carbo)silazanes or polysiloxanes, which upon shaping and pyrolysis lead to silicon carbide (SiC), silicon carbonitride ( $\mathrm{SiCN}$ ) or silicon oxycarbide ( $\mathrm{SiOC}$ ) based ceramic parts. [7] In the first step the preceramic polymer is cross-linked and shaped to furnish micro structured green bodies. In the second step the green bodies are thermally treated in inert or reactive gas atmosphere at temperatures in the range from 1000 to $1400{ }^{\circ} \mathrm{C}$ (pyrolysis step). [8] This processing has been shown to allow for preparing SiCN $[9,10]$ or SiOC based $[11,12]$ ceramic micro components.

\section{Experimental}

A commercially available polysiloxane RD-684 Polyramic $^{\circledR}$ (Starfire Systems Inc.) was used as preceramic polymer. Irgacure $651 \AA$ (Ciba) was used as photoinitiator for the UV crosslinking of the polymer. The elastomeric molds were produced from a polysiloxane, i.e. PDMS Sylgard $184^{\circledR}$ (Dow Corning).

For the photolithographic process, the polysiloxane RD-684, mixed with 5 wt $\%$ of Irgacure 651 (Ciba) was first deposited on a $\mathrm{Si}$ wafer with a spin coater. Subsequently, the sample was irradiated with UV light ( $\mathrm{Hg}$ lamp, I $=12 \mathrm{~mW} / \mathrm{cm}^{2}, \lambda=365 \mathrm{~nm}$ ) for 20 min using a foil mask comprising of microcombs and 
microsquares from $20 \mu \mathrm{m}$ up to $1280 \mu \mathrm{m}$ in size. The photolithographic process was performed in a proximity modus (distance between the mask and the sample $80 \mu \mathrm{m}$ ). The UV irradiation caused cross-linking of the exposed regions and the unexposed regions could be developed with cyclohexane (negative development). The cured microstructured polymer on the $\mathrm{Si}$ wafer was pyrolyzed subsequently at $1100{ }^{\circ} \mathrm{C}$ under argon to obtain ceramic microstructures on silicon wafer showing thicknesses up to $5 \mu \mathrm{m}$ and dimensions down to $40 \mu \mathrm{m}$.

For the soft-lithographic process the first step was the preparation of the master. Two types of masters have been used: thiolene and aluminum masters. The aluminum masters were fabricated with a micro milling cutter. Other metallic masters were formed by an electroplating process using nickel. To produce these masters, the negative resist SU-8 was applied with a thickness of 500 microns onto a conductive substrate and structured upon UV irradiation. The structured resist layer was filled in an electroplating step with nickel. After stripping the resist only the precise metallic form remained. This process allows for producing vertical side walls of the micro structures.

The next step in the soft-lithographic process was the replica molding (RM) of the master to obtain the polydimethylsiloxane mold (PDMS mold). For this purpose, PDMS was first mixed with a cross-linker in a weight ratio 10:1. A metallic box containing the master was filled with this mixture and heated in an oven at $100{ }^{\circ} \mathrm{C}$ for $1 \mathrm{~h}$. Subsequently, the cured PDMS was released from the box and the master and it could be used as soft mold for the next steps of the soft lithographic process. In this procedure, the polysiloxane RD 684 mixed with 5 wt \% of Irgacure 651 was deposited on the surface of the PDMS mold and covered with a glass substrate with a Teflon $®$ coating (DuPont $^{\mathrm{TM}}$ ). The preceramic polymer was irradiated for 20 min under UV light (Hg lamp, I $=30 \mathrm{~mW} / \mathrm{cm}^{2}, \lambda=365 \mathrm{~nm}$ ) in order to achieve the cross-linking of the polymer. After the release from the PDMS mold and the glass substrate, free-standing cured polysiloxane microparts were obtained. In the last step the micro component samples were pyrolyzed at $1100^{\circ} \mathrm{C}$ under argon with a heating rate of $50{ }^{\circ} \mathrm{C} / \mathrm{h}$ between graphite felts in order to allow for homogeneous release of gases and for diminishing cracks occurrence. Thus, SiOC micro components with aspect ratios as high as 3:1 and complex-shaped microstructured parts containing micro channels with different depths (0.4 and $1.2 \mathrm{~mm}$ ) were obtained.

\section{Results and Discussion}

Fig. 1 shows optical images of the mask that was used and of the produced SiOC microsized ceramics on $\mathrm{Si}$ wafer. The ceramic microstructures are well defined with dimensions down to ca. $20 \mu \mathrm{m}$. An approximate value of the critical thickness of the cured polymer on the Si wafer was defined to be around $8 \mu \mathrm{m}$, as microstructures with higher thickness were cracked during pyrolysis. The cracking upon pyrolysis can be understood as an effect of stress occurring due to i) the intrinsic stresses generated via the constrained shrinking of the microstructures on the substrate and ii) the thermal expansion mismatch between the micro structured part and the substrate. [13-15]

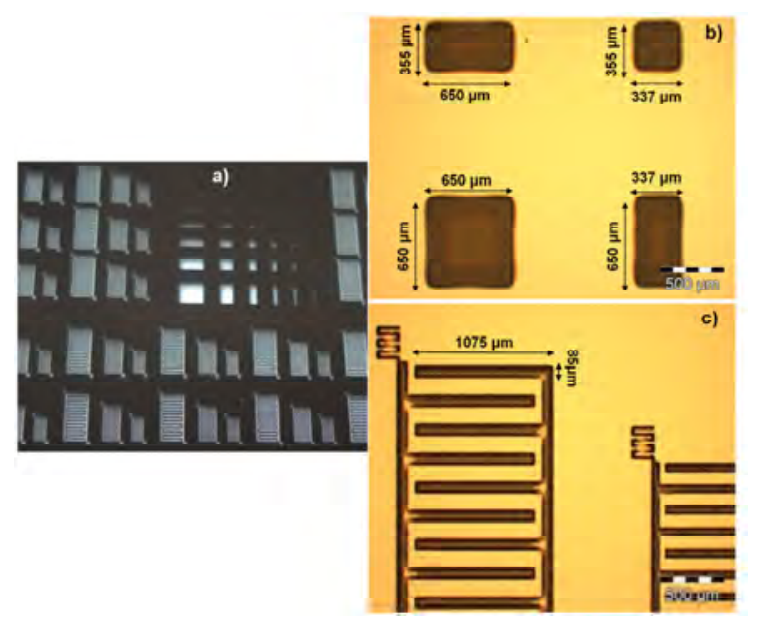

Fig. 1. a) Mask with micro squares and microcombs used for photolithographic processing of SiOC micro components on silicon wafer; b) SiOC-based ceramic micro squares obtained via photolithographic processing of RD 684 and subsequent pyrolysis; c) microcombs (the small microstructures at the edge of the combs have dimensions of $18 \times 190 \mu \mathrm{m})$ [12] (with permission of Elsevier).

Considering the coefficient of thermal expansion of the silicon substrate to be 3.2 $\mathrm{ppm} / \mathrm{K}$ and the CTE of the cured RD 684 based material to be 150 to $250 \mathrm{ppm} / \mathrm{K}$ (measured via TMA upon heating to $500{ }^{\circ} \mathrm{C}$ ), there is a significant thermal stress which might occur upon pyrolysis at lower temperatures, i.e. up to $500{ }^{\circ} \mathrm{C}$. In addition, shrinking occurs at higher temperatures due to polymer-to-ceramic transformation (as it is revealed by the reduction in thickness - upon pyrolysis a zshrinkage of $40 \%$ was recorded), thus high intrinsic tensile stress is expected to occur. 
In our case, crack-free SiOC micro parts deposited on silicon wafer and with thicknesses up to $5 \mu \mathrm{m}$ could be produced after polymer-toceramic transformation.

Free-standing ceramic parts were also prepared and investigated with respect to their volumetric shrinkage upon pyrolysis. The volume shrinkage (49 to $52 \mathrm{vol} \%$ ) as well as the z-shrinkage (approx. 22\%) of the prepared free standing ceramic samples were found to not depend on their $x$ and $y$ dimensions (free shrinkage). The microstructures which were prepared on silicon substrates showed no shrinkage in $x$ and $y$ direction (due to the adhesion of the precursor to the substrate) and high z-shrinkage (40\%). Thus, due to constrained shrinkage, the structures prepared on substrate were found to shrink less in volume (40 vol\%) than the free standing samples (ca. 49 to 52 vol\%) upon pyrolysis.

Taking into account the results obtained upon preparing SiOC ceramic microstructures via photolithographic techniques, one can conclude that this is a simple, efficient and reliable method to prepare free-standing parts as well as microstructures on substrates with dimensions down to a few micrometers. Furthermore, studies on the shrinkage of freestanding parts as well as of micro structured parts on a silicon substrate revealed that the volume shrinkage is higher in the free standing parts if compared with that of the microstructures on substrate. Interestingly, despite the high shrinkage observed in both free-standing parts as well as in the microstructures on substrate, the residual porosity of the prepared ceramics was found to be near zero, as was shown previously. [16]

The soft-lithographic process allows for a precise duplication of the master microstructures to the polysiloxanes without the use of a mask (Fig. 2).

In the first step, the structure of NOA master was replicated onto the PDMS, which can be easily released due to its elastomeric character as well as to its less adhesion to the master. Subsequently, the PDMS mold structure was replicated to the precursor with excellent accuracy since both materials are polysiloxanes. Since insufficient crosslinking causes sticking of the precursor to the PDMS mold, the precursors were irradiated for long time (i.e., $20 \mathrm{~min}$.) to avoid this phenomenon. That way, microstructured ceramic parts with thickness up to $300 \mu \mathrm{m}$ and showing welldefined microholes $(150 \mu \mathrm{m})$ were obtained (aspect ratio 2:1). A linear shrinkage of ca. 30 $\%$ was found for the whole process, from the original size of the holes (in the mask) to the obtained ceramic microholes.
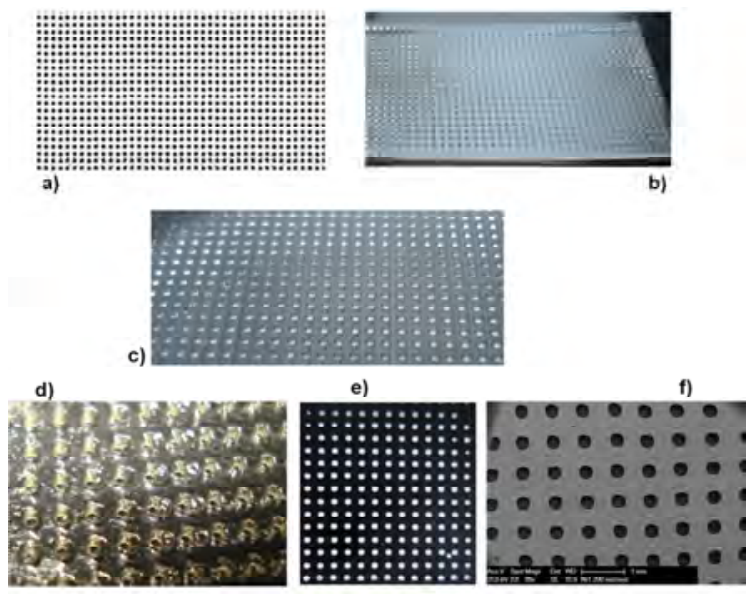

Fig. 2. Processing of microstructured SiOC-based ceramic parts: a) photomask with microholes (radius of $200 \mu \mathrm{m})$; b) NOA 61 master prepared upon photolithographic process; c) PDMS mold obtained via RM; d) cured RD 684-based polymeric part obtained via photo-crosslinking; e) optical image and f) SEM micrograph of SiOC-based ceramic part prepared via pyrolysis in argon atmosphere at $1100{ }^{\circ} \mathrm{C}$ [12] (with permission of Elsevier).

In addition, a free-standing SiOC ceramic microcomponent has also been fabricated via soft lithographic technique using an aluminum mold. Figure 3 shows the different stages during the procedure from the aluminum mold to the ceramic micropart.

After the RM preparation of the PDMS mold (Figure 3b), the polysiloxane-based green micropart was prepared (Figure 3c) and subsequently pyrolyzed in argon atmosphere at $1000{ }^{\circ} \mathrm{C}$ to obtain the SiOC ceramic (Figure $3 d)$. That way the shape of the mold has been excellently duplicated. Moreover, a smooth surface free of macro- and micropores and cracks was obtained, as can be seen in Figures $3 \mathrm{e}$ and $3 \mathrm{f}$. This technique allows for producing complex-shaped components which can hardly or not be produced by other micro structuring approaches. The total linear shrinkage was measured to be $25 \%$. Despite the large shrinkage, the precursor part shrank uniformly and the ceramic kept the shape of the preceramic polymer form without showing cracking or porosity. 


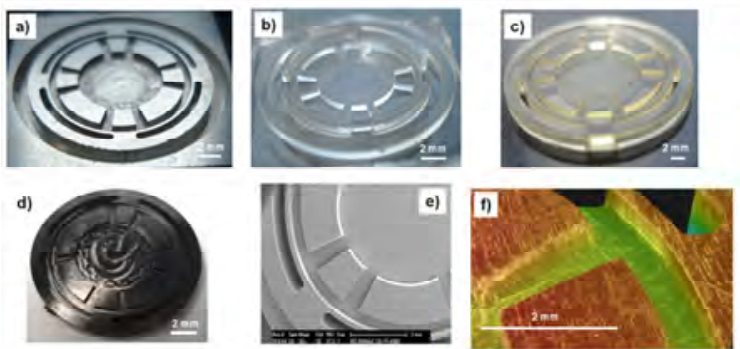

Fig. 3. a) Aluminum mold used for RM preparation of the green microparts; b) PDMS mold obtained via $R M$; c) cured polysiloxane-based green body; d) SiOC ceramic microcomponent obtained upon pyrolysis of the green body; e) SEM micrograph and f) optical picture of the ceramic microcomponent [12] (with permission of Elsevier).

An important advantage of this procedure is the possible reuse of the same PDMS mold several times without damage. Thus, more micro components can be fabricated using the same PDMS mold, which might decrease production time and costs.

\section{Conclusions}

In this paper the fabrication of different SiOC ceramic micro components from a commercial polysiloxane is presented, which was achieved by using two different shaping techniques, i.e. photolithography and soft-lithography, followed by a pyrolysis step. In both cases photocrosslinking has been applied, being a rapid and crack-free procedure to obtain infusible polymers. Thus, aspect ratios as high as 3:1 and minimum micro-sizes of $20 \mu \mathrm{m}$ have been produced. Whereas the photolithographic approach allows for producing microstructures on substrates, the soft lithography technique used was shown to be an excellent and reliable approach to produce free standing and complex-shaped micro components.

\section{Acknowledgements}

The authors thank the European Community FP6 (MCRTN-019601, PolyCerNet) and the Bundesministerium für Bildung und Forschung, Berlin, Germany (BMBF, Grant No. 16SV3724) for the financial support.

\section{References}

[1] R. A. Dorey, S. A. Rocks, F. Dauchy, D. Wang, F. Bortolani, E. Hugo, J. Eur. Ceram. Soc. 28, 13971403 (2008); doi: 10.1016/j.jeurceramsoc.2007.12.003.

[2] P. Kleinschmidt, W. Hanrieder, Sensors and Actuators A 33, 5-17 (1992); doi: 10.1016/0924-4247(92)80217-Q.

[3] M. J. Veellekoop, G. W. Lubking, P. M. Sarro, A. Venema, Sensors Actuators A 44, 249-263 (1994); doi: 10.1016/0924-4247(94)00810-8.

[4] A. Campo, E. Artz, Chem. Rev. 108, 911-945 (2008); doi: 10.1021/Cr050018y.

[5] B. D. Gates, Q. Xu, M. Stewart, D. Ryan, C. G. Willson, G. M. Whitesides, Chem. Rev. 105, 1171-1196 (2005); doi: 10.1021/Cr030076o.

[6] Y. Xia, G. M. Whitesides, Annu. Rev. Mater. Sci. 28, 153-184 (1998); doi: 10.1146/annurev.matsci.28.1.153.

[7] R. Riedel, A. Gurlo, E. lonescu, Chemie in unserer Zeit, 44[3], 208-227 (2010) doi: 10.1002/ciuz.201000512.

[8] E. lonescu, "Polymer-Derived Ceramics", in Ceramics Science and Technology, Eds. R. Riedel, I.-W. Chen, Wiley-VCH 2012, pp 457-500.

[9] G. Feiertag, W. Ehrfeld, H. Freimuth, H. Kolle, H. Lehr, M. Schmidt, M. M. Sigalas, C. M. Soukoulis, G. Kiriakidis, T. Pedersen, J. Kuhl W. Koenig, Appl. Phys. Lett. 71, 1441-1443 (1997); doi: $10.1063 / 1.120431$.

[10] L. Liew, W. Zhang, V. Bright, L. An, M. Dunn, R. Raj, Sensors and Actuators A 89, 64-70 (2001) doi: 10.1016/S0924-4247(00)00545-8.

[11] R. Harshe, C. Balan, R. Riedel, J. Eur. Ceram. Soc. 24, 3471-3482 (2004) doi: 10.1016/j.jeurceramsoc.2003.10.016.

[12] S. Martínez Crespiera, E. Ionescu, M. Schlosser, K. Flittner, G. Mistura, R. Riedel, H. F. Schlaak, Sensors and Actuators A 169, 242-249 (2011) doi: 10.1016/j.sna.2011.04.041.

[13] G. W. Scherer, J. Non-Cryst. Solids 147-148, 363-374 (1992) doi: 10.1016/S0022-3093(05)80645-3.

[14] C. J. Brinker, A. J. Hurd, P. R. Schunk, G. C. Frye, C. S. Ashley, J. Non-Cryst. Solids 147-148, 424-436 (1992) doi: 10.1016/S0022-3093(05)80653-2.

[15] H. Kozuka, S. Takenaka, H. Tokita, T. Hirano, Y. Higashi, T. Hamatani, J. Sol-Gel Sci. Technol. 26, 681-686 (2003) doi: 10.1023/A:1020773415962.

[16] S. Martínez Crespiera, E. Ionescu, H.-J. Kleebe, R. Riedel, J. Eur. Ceram. Soc. 31, 913-919 (2011); doi: 10.1016/j.jeurceramsoc.2010.11.019. 